\section{Comparison of Fusarium solani and $F$. oxysporum as Causal Agents of Fruit Rot and Root Rot of Muskmelon}

\author{
E.R. Champaco' and R.D. Martyn ${ }^{2}$ \\ Department of Plant Pathology and Microbiology, Texas A\&M University, \\ College Station, TX 77843
}

M.E. Miller ${ }^{3}$

Rio Grande Valley Agricultural Center, Texas Agricultural Experiment Station, Weslaco, TX 78596

Additional index words. Cucumis melo, Fusarium oxysporum f. sp. melonis, Fusarium solani f. sp. cucurbitae, melon root rot, melon vine decline

Abstract. Rotting muskmelon fruits commonly are associated with commercial fields that are affected by the root rot/vine decline disease syndrome found in southern Texas. Four isolates of Fusarium solani previously shown to be either weakly pathogenic or nonpathogenic to muskmelon seedlings caused extensive rot on mechanically wounded muskmelon fruits. Two of these isolates caused more extensive fruit rot than either $F$. solani (Mart.) Sacc. f. sp. cucurbitae W.C. Snyder \& H.N. Hans. or F. oxysporum Schlechtend.:Fr. melonis (Leach \& Currence) W.C. Snyder \& H.N. Hans., causal agents of fusarium crown and foot rot of cucurbits and fusarium wilt of muskmelon, respectively. In other tests, root-dip inoculation of seedlings showed that all muskmelon cultigens included in this study and the breeding line MR-1 were susceptible to a California and an Arkansas strain of $F$. s. f. sp. cucurbitae race 1.

In 1986, muskmelon producers in the Lower Rio Grande Valley (LRGV) of southern Texas suffered high economic losses due to root rot/ vine decline disease, locally referred to as root rot (Champaco, 1990; Champaco et al., 1988). The disease has persisted through the 1993 season (information added during manuscript revision). Symptoms include leaf yellowing and dieback of the crown leaves, cortical rot of the taproot and lateral roots, and discoloration of the vascular system in the roots and crown, The disease has symptoms similar to fusarium wilt (caused by Fusarium oxysporum f. sp. melonis) and fusarium crown and foot rot (caused by $F$. solani $\mathrm{f}$. sp. cucurbitae). However, based on several experiments performed under greenhouse conditions, numerous $F$. solani and $F$. oxysporum isolates recovered from taproots and lateral roots of infected field-grown muskmelon plants were nonpathogenic on various muskmelon cultivars, suggesting that these fungi were probably not the causal agents of root rot (Champaco, 1990). Recently, Mertely et al. (1991 and 1993) showed that Monosporascus

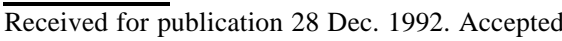
for publication 5 Aug. 1993, Funding for this research was provided in part by the South Texas Melon Committee and the Texas Agriculture Experiment Station. The cost of publishing this paper wasdefrayedinpartbythe payment of page charges. Under postal regulations, this paper therefore must be hereby marked advertisement solely to indicate this fact.

${ }^{1}$ Former Graduate Research Assistant.

${ }^{2}$ Professor.

${ }^{3}$ Associate Professor. cannonballus Pollack \& Uecker was the primary casual agent of this disease.

Isolates of $F$. solani were recovered three to ten times more frequently from roots of plants showing symptoms of root rot (Champaco, 1990; Mertely et al., 1991) than were $F$. oxysporum isolates. Additionally, rotted fruits were often associated with the presence of root rot in commercial muskmelon fields, and these Fusarium spp. may serve as potential fruit rot pathogens. A previous report by Godfrey (cited in Toussoun and Snyder, 1961) cited F. solani as a dominant factor in rotting mature melon fruits under wet weather conditions in Texas. Fusarium o. f. sp. melonis (race 0) has been reported in Texas (Martyn et al., 1987); however, there has been no prior report of $F$. s. f. sp. cucurbitae in the state. Additionally, numerous isolates of $F$. solani taken from roots of muskmelon plants showing root-rot symptoms were not pathogenic in greenhouse inoculation studies, which suggests that $F$. s. f. sp. cucurbitae most likely is not a causal agent of root rot in Texas (Champaco, 1990).

Fusarium crown and foot rot disease was first reported on squash (Cucurbitapepo L.) in 1930 in South Africa (Doidge and Kresfelder, 1932). The disease has since been reported in the Americas, Europe, and Australia (Sherf and MacNab, 1986). It was reported on cucumber (Cucumis sativus L.) in glasshouses in the Netherlands in 1960 (Paternotte, 1987) and reappeared there in 1980, causing foot rot in courgette (Cucurbita pepo L.). Fusariums. f. sp. cucurbitae is not as widespread in the United States as is $F$. $o$. f. sp. melonis. The first report of $F$. s. f. sp. cucurbitae in the United
States was in California in 1938 (Snyder, 1938). In 1970, Sumner (1976) isolated the pathogen from summer squash (Cucurbita реро var. melopepo) in Georgia. In 1978, Boyette et al. (1984) isolated a strain of F.s. f. sp. cucurbitae from Texas gourd [Cucurbita texana (A.) Gray] in Arkansas. Much of the interest in F. S. f. sp. cucurbitae in Arkansas is in its potential as a biocontrol agent for Texas gourd, a persistent weed problem in cotton (Gossypium hirsutum L.) and soybean [Glycine $\max (\mathrm{L}$.$) Merr.] (Boyette et al., 1984;$ Weidemann and Templeton, 1988).

There are two described races of F.s. f. sp. cucurbitae (Toussoun and Snyder, 1961); however, recent work (Van Etten and Kistler, 1988) has separated these into two differing mating populations (MP), which most probably are different species. Race 1 is a root-, stem-, and fruit-rot pathogen; occurs worldwide; and is in MP-I. Race 2, which is pathogenic primarily to mature cucurbit fruits, has only been described from the United States (California and Ohio) and is included in MP-V. Pathogenic-isolates of $F$. s. f. sp. cucurbitae are generally heterothallic. The teleomorph is Nectria haematococca Berk. \& Broome. Fusarium crown and foot rot has been reported only on pumpkin, squash, and marrow under field conditions; however, other cucurbitaceous hosts are susceptible under greenhouse inoculation conditions (R. D. M., unpublished; Tousson and Snyder, 1961). There is no identified resistance to F.s. f. sp. cucurbitae among the cultivated muskmelons.

The development of muskmelon breeding lines PI-124111F by Cohen and Eyal (1987) in Israel and MR-1 by Thomas (1986) in the United States has stimulated considerable interest in muskmelon breeding. Both breeding lines were derived from PI- 124111 and have resistance to powdery mildew [Sphaerotheca faliginea (Schlechtend.:Fr) Pollacci], downy mildew [Pseudoperonospora cubensis (Berk. \& M.A. Curtis) Rostovzev], and to races 0, 1, and 2 of F. o. f. sp. melonis (Zink and Thomas, 1990). The disease reaction of these lines to $F$. $s$. f. sp. cucurbitae has not been reported.

The objectives of the present study were to 1) compare the relative abilities of several isolates of $F$. oxysporum and $F$. solani to cause fruit rot under laboratory conditions and 2) evaluate the disease reaction of commercial muskmelon cultigens, germplasm, and MR-1 to two geographic isolates of $F$. $s$. f. sp. cucurbitae race 1 (California and Arkansas).

The fusarium strains used were obtained from the stock collection maintained at the Fusarium Laboratory at Texas A\&M Univ. The isolate of $F . o$. f. sp. melonis race 0 originated from Maryland (E. Dutky, Univ. of Maryland, College Park). Two isolates of F.s. f. sp. cucurbitae race 1 were used. One was from California (J. Watterson, Petoseed Co., Woodland, Calif.) and the other from Arkansas (G. Weidemann, Univ. of Arkansas, Fayetteville). Four Fusarium solani isolates obtained from roots of infected muskmelon plants in commercial fields in Texas were used: 1A-la, 34B-1, 63C-2, and 0629. All $F$. solani isolates, except the two crown and foot- 
rot isolates, included in this study were nonpathogenic or only weakly pathogenic on muskmelon seedlings in a previous greenhouse inoculation study (Champaco, 1990). Each isolate was maintained as single-spored cultures in sterile soil (McKeen and Wensley, 1961). Seeds of the cultivars and hybrids were obtained from commercial seed companies. The fusarium wilt host differentials, Doublon and 1088 CM 17-187, were obtained from F. Zink (Univ. of California, Davis). MR-1 was obtained from C. Thomas (U.S. Dept. of Agriculture/Agricultural Research Service, Charleston, S.C.).

Inoculum of each Fusarium isolate was increased by placing several granules of soil culture in $50 \mathrm{ml}$ of fusarium mineral salts liquid medium (Esposito and Fletcher, 1961) contained in a 250-ml Erlenmeyer flask. The inoculum was incubated on a rotary shaker at $100 \mathrm{rpm}$ held at $25 \pm 2 \mathrm{C}$ under continuous fluorescent light $\left(860 \mu \mathrm{mol} \cdot \mathrm{m}^{-2} \cdot \mathrm{s}^{-1}\right)$ for 3 to 4 days. After incubation, the conidia were filtered through eight layers of sterile cheesecloth, and the conidial suspension was adjusted to $1 \times 10^{6}$ microconidia/ml using a hemacytometer.

The isolates used in the fruit-rot study were 1A-la, 34B-1, 63C-2, 0629, F. s. f. sp. cucurbitae race 1 (California), and $F$. o. f. sp. melonis race $\mathrm{O}$. Ripe muskmelon fruit (cultivar unknown) purchased from a local grocery store were washed and flamed with $70 \%$ ethanol. Five wounds, $7 \mathrm{~mm}$ in diameter were made on the surface of each fruit with a ethanol-flamed cork borer. Wounds were located at the stem end and blossom end of the fruit, and at three other locations around the circumference of the fruit. At each wound location, the plug of fruit was removed and 25 $\mu \mathrm{l}$ of fungal inoculum $\left(1 \times 10^{6}\right.$ suspension $)$ was placed in the exposed flesh. The plugs were replaced to cover the holes after inoculation. Each fruit was inoculated with one isolate and there were three one-fruit replications for each isolate. Each fruit was covered with a clear plastic bag for $24 \mathrm{~h}$ and set on petri dishes (80 x $100 \mathrm{~mm})$ maintained in a darkened growth room at ambient temperature (20C). At the end of $24 \mathrm{~h}$, the plastic bags were removed, humidifiers and growth lights (12-h light/day cycle) were turned on, and the temperature maintained at $\approx 22 \mathrm{C}$. Fruits were incubated under these conditions for 10 days. Length of time required for initial rot development, and the mean depth and mean maximum diameter (severity) of the rot caused by each isolate were recorded. The data were subjected to analysis of variance (ANOVA) and the means separated according to Duncan's multiple range test $(\mathrm{et}=0.05)$.

Hybrid muskmelons are becoming increasingly more important in commercial production in Texas; however, no data on the disease response to $F$. s. f. sp. solani are available on these hybrids. In addition, MR-1 has received considerable attention because of its good resistance to several diseases. Therefore, muskmelon cultigens were tested against two strains of F.s. f. sp. cucurbitae. Seeds of the commercial cultigens were surface-disinfected in $10 \%$ bleach $(0.525 \% \mathrm{NaOCl})$ for $60 \mathrm{see}$, rinsed in sterile distilled water, and planted in seedling flats containing a 4 vermiculite $: 4$ perlite :1 peatmoss (by volume) potting mixture. At emergence of the first true leaves ( $\approx 10$ days), seedlings were uprooted and the roots gently washed under running water to remove the surrounding potting medium. Seedling roots were dipped in the respective inoculum or water (the control treatment) for 20 to $30 \mathrm{sec}$ and transplanted into 1.25-liter $(15-\mathrm{cm}$ diameter) pots containing an 8 pasteurized sand $: 2$ vermiculite :2 perlite : 1 peatmoss mixture. Depending on the number of available seedlings, there were two, three, or four seedlings per pot, and three or four replications of each treatment. Inoculated seedlings were maintained under greenhouse conditions for 4 weeks. Observations were made at 1-to 2-day intervals and the percentage of dead plants recorded. Due to time and space limitations, all cultivars were not included in any one test. However, two internal standard cultivars were included in each test; there was no significant difference in disease seventy between tests, which indicates there was no cultivar $x$ experiment interaction. Consequently, the data presented in Table 1 are the combined data of two experiments performed over 1 year. Doublon, 1088 CM17-187, 'Perlita', and 'Topmark' were the fusarium wilt host differentials used to identify the various races of $F$. $o$. f. sp. melonis. Data were transformed by arcsin transformation and weighted before ANOVA. The means were separated using Fisher's LSD test $(\alpha=0.05)$.

All isolates caused rot in the muskmelon fruit (Fig. 1). Mycelial growth was evident 4 days after inoculation at all wound locations and initial symptoms of rot also were present at that time. Fusarium solani isolate 34B-1 caused the most extensive rot, with $5.5 \mathrm{~cm}$ mean maximum diameter and $3.4 \mathrm{~cm}$ mean maximum depth of lesions (Fig. 2 A and B).

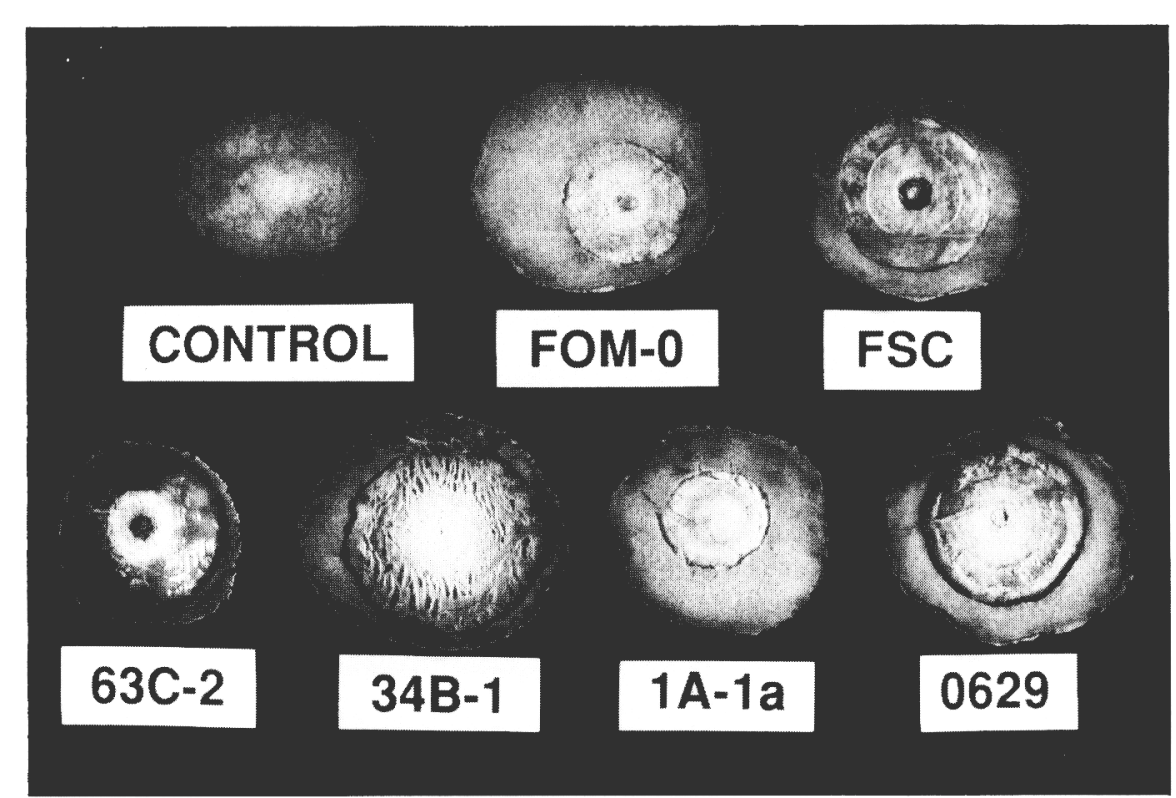

Fig. 1. Comparison of Fusarium oxysporum f. sp. melonis, $F$. solani f. sp. cucurbitae, and other Fusarium solani isolates in causing fruit rot of muskmelon as shown by the inner portion of inoculated fruits. Each fruit slice represents the first outer 5- to $10-\mathrm{mm}$ depth.
Fusarium o. f. sp. melonis caused the least amount of rot, with $3.8 \mathrm{~cm}$ mean maximum diameter and $2.3 \mathrm{~cm}$ mean maximum depth. The extent of fruit rot caused by isolate 34B-1 and $F$. o. f. sp. melonis was statistically $(\alpha=$ $0.05)$ different. All remaining isolates caused ent from each other in mean maximum depth, except when compared to the water control (Fig. 2B). Fruit rot severity, based on inoculation site, did not differ, as rot seventy in the stem end, blossom end, or along the circumference of the fruit was similar. Initial observations, however, showed that fungus colonized the stem end and along the fruit circumference before colonizing the blossom end. A musky odor was associated with fruit inoculated with the test isolates, but not with fruit inoculated with $F$. o. f. sp. melonis or water.

The absence of any statistical difference in fruit rot severity based on inoculation site is due perhaps to wounding before inoculation, which allowed the isolates an equal opportunity, in spite of location, to colonize the fruit. We presumed that, under field conditions, the pathogen enters the fruit through natural wounds (netting cracks) or from wounds caused by injury due to insects, wind-blown sand, or mechanical disturbances. In general, $F$. solani isolates that are only weakly pathogenic or nonpathogenic to seedlings apparently can be extensive fruit rotters. Isolates $34 \mathrm{~B}-1$ and $63 \mathrm{C}-2$ caused more extensive fruit rot than either $F$. s. f. sp. cucurbitae or $F$. o. f. sp. melonis. Pathogenicity of these two $F$. solani isolates to young plants, however, is questionable. In an (Champaco, 1990), isolates 34B-1 and 63C-2 caused severe stunting and necrotic petioles, respectively, in young muskmelon seedlings. However, when a similar study was repeated, none of these symptoms occurred and only slight necrosis was observed on the roots. fruit rot, but they were not statistically differearlier greenhouse inoculation study 
A

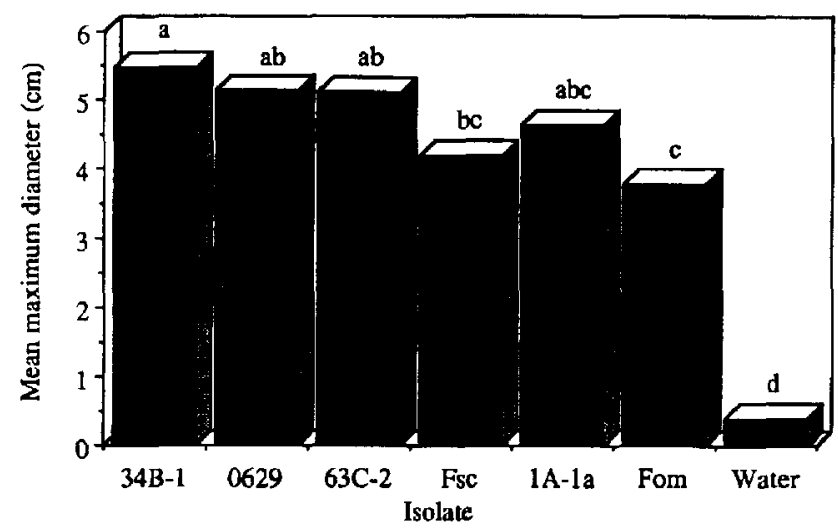

B

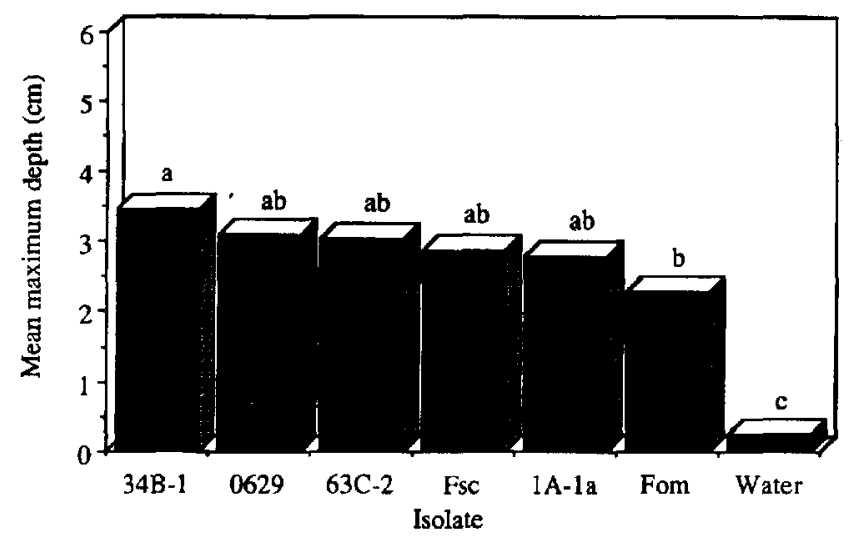

Fig. 2. Severity of muskmelon fruit rot caused by various isolates of Fusarium spp. (A) Mean maximum diameter of lesion. (B) Mean maximum depth of rot. Fsc $=$ Fusarium solani f. sp. cucurbitae (race 1, California strain); Fom $=$ Fusarium oxysporum $\mathrm{f}$. sp. melonis race 0 (Maryland). All other isolates of $F$. solani were from roots of plants collected in Texas.

We conclude from the current fruit-rot study that apparently saprophyticisolates of $F$. solani originating from root-rot-infected muskmelon plants can cause extensive rot on muskmelon fruit. However, Toussoun and Snyder (1961) were unable to cause fruit rot symptoms on muskmelon or watermelon [Citrullus lanatus (Thunb.) Matsum. \& Nakai] with a saprophytic isolate of $F$. solani obtained from a noncucurbitaceous host. Additionally, they observed no lesions on mature ornamental gourd (Cucurbita pepo v. ovifera Alef.) or white bush scallop squash (C. pepo L.) fruit when they were set directly on top of saprophyteinfested soil. In contrast, lesions did develop when soil was infested with either race of $F$.s. f. sp. cucurbitae.

According to Toussoun and Snyder (1961), Godfrey reported that $F$. solani was a dominant factor in mature melon fruit rotting under wet weather in Texas. He concluded that the $F$. solani isolate used was more similar to race 2 of F.s. f. sp. cucurbitae in culture characteristics and was not pathogenic to plants. In contrast, the isolate was more effective than race 2 in rotting muskmelon fruits and apparently did not sexually cross with race 2 . In the present study, the differences in fruit rot severity between $F$. solani isolates and $F$. s. f. sp. cucurbitae race 1 , with the exception of $34 \mathrm{~B}-1$, were not statistically significant. In general, the test isolates caused more fruit rot than F.s. f. sp. cucurbitae. The $F$. solani isolates used in this study are aggressive fruit rotters and may be similar to those described by Godfrey (Toussoun and Snyder, 1961).

Fruit rot remains prevalent throughout the LRGV, and based on the present study, $F$. solani could be a dominant factor. Infected fruit are often tilled into the soil and may serve as a reservoir for growth and multiplication of $F$. solani. The high degree of association of $F$. solani with root lesions caused by Monosporascus cannonballs (Champaco, 1990; Mertely et al., 1991) may, in turn, provide the necessary inoculum for fruit infection.

Little variation was observed in disease response among the various lines screened (Table 1). All cultigens tested were highly susceptible to both strains of $F$. $s$. f. sp. cucurbitae. None of the plants in the water control treatments died. All four fusaritum wilt differentials, except Doublon, were equally susceptible (all plants died) to the Arkansas and California isolates. Only $50 \%$ of the Doublon plants died when inoculated with the California strain. Although statistically significant, we consider this an anomaly because Doublon has shown no resistance to F.s. f. sp. cucurbitae in other tests (data not shown). Based on the results of these tests, the two $F$. s. f. sp. cucurbitae strains had similar effects on their hosts, and no resistance was identified in any of the cultigens tested. These experiments also have shown that MR-1 is highly susceptible to race 1 of F.s. f. sp. cucurbitae. Although this information is disappointing, this breeding line is still valuable in that it is the only germplasm, other than PI-124111F (Cohen and Eyal, 1987), with resistance to races 0,1 , and 2 of $F$. o. f. sp. melonis (Zink and Thomas, 1990). An additional advantage of MR-1 is its high level of resistance to powdery mildew and downy mildew (Thomas, 1986) and to Alternaria cucumerina (Ellis \& Everh.) J.A. Elliot (Thomas et al., 1990).

The Arkansas strain of $F$. s. f. sp.cucurbitae used in this study was isolated from Texas gourd seeds and seedlings (Boyette et al., 1984). Texas gourd is a problem weed in cotton and soybean in Arkansas, and researchers there have shown $F$. s. f. sp. cucurbitae to bean effective biocontrol agent (Boyette et al., 1984; Weidemann and Templeton, 1988). These same studies also showed that the pathogen survived poorly in the soil and did not persist for more than 12 months. In contrast, Nash and Alexander (1965) reported that F.s. f. sp. cucurbitae survived at least 19 months in artificially infested soil, and Sumner (1976) found that it survived for as long as 20 months in naturally infested fields in Georgia.

Pathogenicity tests revealed a limited host range for F.s. f. sp. cucurbitae (Boyette et al., 1984). Pathogenicity tests performed at our laboratory (Champaco, 1990; R. D. M., unpublished), however, showed that, in addition to squash, numerous commercial muskmelon cultivars and 'Black Diamond' watermelon

Table 1. Comparison of disease reaction of muskmelon seedlings inoculated at 2 weeks old with twoisolatesof Fusarium solani f. sp. cucurbitae race 1 .

\begin{tabular}{lcc}
\hline & \multicolumn{2}{c}{ Dead plants (\%) } \\
& \multicolumn{2}{c}{ Isolate } \\
Germplasm & California & Arkansas \\
Doublon & $50 \mathrm{~b}^{2}$ & $100 \mathrm{a}$ \\
1088CM17-187 & $83 \mathrm{a}$ & $100 \mathrm{a}$ \\
Perlita & $100 \mathrm{a}$ & $100 \mathrm{a}$ \\
Topmark & $100 \mathrm{a}$ & $100 \mathrm{a}$ \\
Aragon & $100 \mathrm{a}$ & --- \\
Challenger & $88 \mathrm{ab}$ & $100 \mathrm{a}$ \\
Easy Rider & $100 \mathrm{a}$ & $84 \mathrm{a}$ \\
Explorer & $100 \mathrm{a}$ & --- \\
Grande Gold & --- & $100 \mathrm{a}$ \\
Hiline & $100 \mathrm{a}$ & $100 \mathrm{a}$ \\
HMX 5601 & $100 \mathrm{a}$ & $100 \mathrm{a}$ \\
Hymark & $100 \mathrm{a}$ & $100 \mathrm{a}$ \\
Laguna & $94 \mathrm{a}$ & --- \\
Magnum 45 & $91 \mathrm{ab}$ & $100 \mathrm{a}$ \\
Mission & $100 \mathrm{a}$ & $92 \mathrm{ab}$ \\
MR-1 & $100 \mathrm{a}$ & --- \\
Producer & $100 \mathrm{a}$ & $100 \mathrm{a}$ \\
PSX 1983 & $100 \mathrm{a}$ & $100 \mathrm{a}$ \\
PSX 2083 & $100 \mathrm{a}$ & $100 \mathrm{a}$ \\
Sunshine & --- & $100 \mathrm{a}$ \\
Topflight & --- & $96 \mathrm{a}$ \\
XPH 5363 & --- & $94 \mathrm{a}$ \\
XPH 5264 & --- & $100 \mathrm{a}$
\end{tabular}

XPH 5264

Means followed by the same letters within columns are not statistically different based on Fisher's LSD test $(\alpha=0.05)$.

${ }^{y}$ Not included in the study. 
[determined resistant by Boyette et al. (1984)] were susceptible to F.s. f. sp. cucurbitae. The impact on the use of $F$. s. f. sp. cucurbitae as a biological control agent requires careful consideration. In spite of its appealing characteristics, which make this pathogen an attractive alternative to the use of chemical control, introducing this pathogen, especially to soils where it does not already exist, presents serious problems to cucurbit growers not only in Arkansas, but in neighboring states such as Texas, where muskmelon and watermelon are major production crops. Boyette et al. (1984) acknowledge that the pathogen is spread in the field, but, as yet, the mechanism of spread has not been fully determined. Based on previous work (Champaco, 1990), F.s. f. sp. cucurbitae has not been detected in Texas. However, the use of $F$. s. f. sp. cucurbitae as a biocontrol agent for weeds could spread the pathogen through infected seed or infested soil. The pathogen can be seed-borne to a high degree and lies dormant between the seedcoat and cotyledons (Toussoun and Snyder, 1961). The possibility remains that if $F$.s. f. sp. cucurbitae is used as a biocontrol for Texas gourd, it could spread to Texas in the near future.

\section{Literature Cited}

Boyette, C.D., G.E. Templeton, and L.R. Oliver. 1984. Texas gourd (Cucurbita texana) control with Fusarium solani f. sp. cucurbitae. Seed Sci. 32:649-455.
Champaco, E.R. 1990. An investigation of the etiology of the root rot-wilt disease of muskmelon in the Lower Rio Grande Valley of Texas. MS Thesis, Texas A\&M Univ., College Station.

Champaco, E.R., R.D. Martyn, L.W. Barnes, M.E Miller, J. M. Amador, and A. Perez. 1988. Root rot, anew disease of muskmelon in South Texas. Phytopathology 78:626. (Abstr.)

Chupp, C. 1939. Vegetable disease notes in New York. Plant Dis. Rptr. 23:218-219.

Cohen, Y. and H. Eyal. 1987. Downy mildew-, powdery mildew- and fusarium wilt resistant muskmelon breeding line PI-124111F. Phytoparasitica 15:187-195.

Doidge, E.M. and J. Kresfelder. 1932. A wilt disease of cucurbits. Farming S. Africa 7:299-300.

Esposito, R. and A.M. Fletcher. 1961. The relationship of pteridine biosynthesis to the action of copper 8-hydroxy-quinolate on fungal spores. Arch. Biochem. Biophys. 93:369-376.

Martyn, R.D., L.W. Barnes, and J. Amador. 1987. Fusarium wilt ( $F$. oxysporum f. sp. melonis race 0) of muskmelon in Texas. Plant Dis. 71:469.

McKeen, C.C. and R.N. Wensley. 1961. Longevity of Fusarium oxysporum in soil culture. Science 1341528-1529.

Mertely, J. C., R.D. Martyn, M.E. Miller, and B.D. Bruton. 1991. Role of Monosporascus cannonballus and other fungi in a root rot/vine decline disease of muskmelon. Plant Dis. 75:1133-1137.

Mertely, J.C., R.D. Martyn, M.E. Miller, and B.D Bruton. 1993. Unexpanded host range for the muskmelon pathogen, Monosporascus cannonballus. Plant Dis. 77:667-673.

Nash, S.M. and J.V. Alexander. 1965. Comparative survival of Fusarium solani f. cucurbitae and $F$. solani f. phaseoli in soil. Phytopathology 55:963966.

Paternotte, S.J. 1987. Pathogenicity of Fusarium solani f. sp. cucurbitae race 1 to courgette. Neth. J. Plant Pathol. 93:245-252.

Sherf, A.F. and A.A. Macnab. 1986. Vegetable diseases and their control. 2nd ed. Wiley, New $\mathrm{Y}$ o $\mathrm{r} \mathrm{k}$.

Snyder, W.C. 1938. A fusariun footrot of Cucurbita. Phytopathology 28:19. (Abstr.)

Sumner, D.R. 1976. Etiology and control of root rot of summer squash in Georgia. Plant Dis. Rptr. 60:923-927.

Thomas, C.E. 1986. Downy and powdery mildew resistant muskmelon breeding line MR. 1. HortScience 21:329.

Thomas, C.E., J.D. McCreight, and E.L. Jourdain. 1990. Inheritance of resistance to Alternaria cucumerina in Cucumis melo line MR-1. Plant Dis. 74868-870.

Toussoun, T.A. and W.C. Snyder. 1961. The pathogenicity, distribution, and control of two races of Fusarium (Hypomyces) solani f. cucurbitae. Phytopathology51:17-22.

Van Etten, H.D. and H.C. Kistler. 1988. Nectria haematococca, mating populations I and VI, p. 180-206, In: D.S. Ingram and P.H. Williams (eds.). Advances in plant pathology. vol. 6 . Academic, London.

Weidemann, G.J. and G.E. Templeton. 1988. Efficacy and soil persistence of Fusarium solani f. sp. cucurbitae for control of Texas gourd (Cucurbita texana). Plant Dis. 72:36-38.

Zink, F.W. and C.E. Thomas. 1990. Genetics of resistance to Fusarium oxysporum f. sp. melonis races $\mathrm{O}, 1, \& 2$ in muskmelon line MR-1. Phytopathology 80:1230-1232. 